\title{
Molecular Techniques for MRSA Typing: Current Issues and Perspectives
}

P. A. Trindade, J. A. McCulloch,
G. A. Oliveira and E. M. Mamizuka
Faculty of Pharmaceuthical Science, University of São Paulo, São Paulo, Brazil

\begin{abstract}
Staphylococcus aureus has long been recognised as an important pathogen in human disease. Serious staphylococcal infections can frequently occur in inpatients and may lead to dire consequences, especially as to therapy with antimicrobial agents. The increase in the frequency of Methicillin-Resistant Staphylococcus aureus (MRSA) as the causal agent of nosocomial infection and the possibility of emergence of resistance to vancomycin demands a quick and trustworthy characterization of isolates and identification of clonal spread within hospitals. Enough information must be generated to permit the implementation of appropriate measures for control of infection, so that outbreaks can be contained. Molecular typing techniques reviewed in this manuscript include: plasmid profile analysis, analysis of chromosomal DNA after enzymatic restriction, Southern blotting, pulsed field gel electrophoresis (PFGE), techniques involving polymerase chain reaction and multilocus sequence typing (MLST). Repetitive DNA Sequence PCR (repPCR) may be used for screening due to its practicality, low cost and reproducibility. Because of its high discriminatory power Pulsed-Field Gel Electrophoresis (PFGE) still remains the gold standard for MRSA typing. New techniques with higher reproducibility and discriminatory power, such as Multi-Locus Sequence Typing (MLST), are appearing. These are mostly useful for global epidemiology studies. Molecular typing techniques are invaluable tools for the assessment of putative MRSA outbreaks and so should be extensively used for this purpose.

Key Words: Staphylococcus aureus, molecular epidemiology, genotyping, methicillin resistance.
\end{abstract}

Staphylococcus aureus has long been recognised as being an important pathogen in human disease. Serious staphylococcal infections can frequently occur in inpatients and may lead to dire consequences, especially for therapy with antimicrobial agents [1]. Staphylococcus aureus has been identified as the most common etiological agent of nosocomial infection between 1990 and 1996 by the National Nosocomial Surveillance System (USA), causing principally, nosocomial pneumonia and surgical wound infections [2].

During the last decade, there has been an increase in the proportion of infections caused by MethicillinResistant Staphylococcus aureus (MRSA) in both

Received on 15 May 2002; revised 18 November 2002.

Address for correspondence: Dr. Elsa Masae Mamizuka. Av. Prof. Lineu Prestes, 580 B17, São Paulo - SP, Zip Code: 05508900, Brazil. Phone: (+5511) 30913663. Fax: (+5511)3813-2197.

The Brazilian Journal of Infectious Diseases 2003;7(1):32-43 (C) 2003 by The Brazilian Journal of Infectious Diseases and Contexto Publishing. All rights reserved. inpatients and outpatients [3-5]. Over 95\% of patients with staphylococcal infections, worldwide, do not respond to therapy with penicillin or ampicillin [2].

Reported for the first time in the 1960s [6], MRSA became ever more prevalent in the 1980s and is currently endemic in various hospitals [2].

In Brazil, the frequency of isolation of Staphylococcus aureus and its role in nosocomial infection has been greater than in other countries [11]. Staphylococcus aureus has been pointed out as being the agent responsible for $19 \%$ of the nosocomial infections at the Hospital São Paulo, $60 \%$ of the isolates being MRSA [12]. Sader et al. [13] found a prevalence of approximately 70\% MRSA among Staphylococcus aureus isolates in some hospitals of the metropolitan area of São Paulo. Caiaffa et al. [14] found that at the Hospital das Clínicas da FMUSP $40 \%$ of the Staphylococcus aureus isolates from outpatients and $70 \%$ of the isolates from inpatients were resistant to methicillin. 
The increase in the frequency of MRSA as the causal agent of nosocomial infection and the possibility of emergence of resistance to vancomycin demands quick and trustworthy characterization of the isolates and an investigation of clonal spreading within hospitals, so that enough information is generated to permit the implementation of appropriate measures for the control of these infections, allowing for the containment of an outbreak [15]. MRSA isolates from numerous geographical locations seem to be derived from only a small number of strains, and consequently belong to a genetically restrict group [16]. The same does not apply to methicillin susceptible Staphylococcus aureus (MSSA) isolates, which have considerable genetic diversity [17-19]. In a study carried out by Oliveira [11], involving 26 hospitals from five different regions in Brazil, $77 \%$ of the MRSA strains were characterized as belonging to an endemic clone, Brazilian Endemic Clone " $\mathrm{A}$ ". One of the characteristics of this clone is its strong capability of spreading within a hospital environment and its high levels of resistance, when compared to other clones. Schmitz et al. [15] pointed out that techniques used for MRSA typing should ideally possess a high discriminatory power due to the low genetic variability presented by these strains.

\section{Objectives}

The aim of this review is to discuss the currently available molecular techniques used for MRSA typing in order to contribute to the understanding of the epidemiology of MRSA, aiding researchers and professionals in the implementation of measures for the control of nosocomial infection. This review will also aid in electing the most adequate control techniques.

\section{Typing Techniques}

Currently, there are numerous typing techniques for the discrimination of Staphylococcus aureus isolates, which can be applied as invaluable tools by both the clinician and the epidemiologist. The greatest challenge for a clinical laboratory is to carry out an analysis that can reliably group epidemiologically related strains and discriminate them from unrelated strains. Usually, these typing systems are used for the investigation of outbreaks of nosocomial infection, and furthermore can aid in the clinical treatment of a patient, allowing for discrimination between successive and recurrent infections, and in a broader context they contribute to the understanding of the epidemiology of infections [20,21].

The criteria for the evaluation of typing techniques can be divided into two categories: performance criteria (efficacy) and convenience criteria (efficiency). Performance criteria include typeability, reproducibility, discriminatory power and agreement between typing techniques, whereas versatility, rapidity, ease of execution and interpretation are considered to be convenience criteria. Typeability means the proportion of isolates that can be assigned as belonging to a "type" by a typing technique. Reproducibility refers to the ability of a technique to yield the same result when the same sample is repeatedly tested. Discriminatory power depends on the probability that isolates sharing identical or intimately related profiles are in fact clonal and part of the same chain of transmission, and hence this is a key characteristic for a typing technique [22,23]. The agreement between two typing techniques can be evaluated by determining if highly similar isolates are grouped accordingly by these techniques [22].

In addition to its intrinsic performance when applied to a microbial pathogen, a typing technique must have practical advantages. Versatility, that is, its ability to type any pathogen with modifications of the protocol, is a very important advantage for the study of nosocomial infection. Other practical aspects include ease of execution and interpretation of results, as well as cost and availability of reagents and equipment [22-24].

Several genotypic techniques have been developed in the last decades. Initially, these techniques were only used by a few research laboratories, but they have been increasingly employed in clinical practice [24].

\section{$\underline{\text { Plasmid Profile Analysis }}$}

Analysis of bacterial plasmids was the first molecular technique used for the epidemiological investigation of MRSA. This technique consists in the extraction of 
plasmid DNA and subsequent separation of this DNA by electrophoresis in agarose gels. It is an easily executed and interpreted technique, however it has several limitations, especially inherent to the fact that plasmids are mobile extrachromosomal elements that can be spontaneously lost or readily acquired by bacteria. Consequently, epidemiologically related isolated can display different plasmid profiles. Moreover, many plasmids carry resistance determinants contained in transposons that can be readily lost or acquired, quickly altering the composition of plasmid DNA. The reproducibility of the generated profiles can be affected by the fact that plasmids exist in different spatial conformations (supercoiled, nicked, and linear), which possess different migration velocities when submitted to agarose gel electrophoresis [25].

Both the reproducibility and discriminatory power of plasmid profile analysis can be substantially enhanced by carrying out enzymatic restriction of the plasmids, as this procedure favours the demonstration of differences in the position and frequency of restriction sites between two non-related plasmids, even though they might share the same molecular mass [25].

The majority of MRSA isolates carry plasmids, but when these are absent the isolates are considered nontypeable. Another limitation is the number of plasmids present in these isolates, usually one or two, which leads to poor discrimination between them $[21,26]$.

Analysis of Chromosomal DNA after Enzymatic $\underline{\text { Restriction (REA) }}$

In this technique, chromosomal DNA is subjected to digestion by restriction endonucleases and the resulting fragments are separated by conventional agarose gel electrophoresis. Restriction endonucleases $B g l I I$ and EcoRI are used for MRSA, as they act on frequently encountered sites along the chromosome, producing short and multiple fragments [27]. After electrophoresis, a set of profiles can be compared to those of other isolates [26]. All MRSA isolates are typeable by this method and the restriction profile consists of numerous overlapping fragments, which makes consistent analysis of results difficult [21,26,28].
Analysis of Chromosomal DNA by Hybridisation with a Nucleic Acid Probe (Southern Blotting)

Following digestion with high frequency restriction endonucleases (REA), chromosomal DNA is separated into a series of fragments of different sizes, characterizing restriction fragment length polymorphisms (RFLP). This type of polymorphism is difficult to interpret due to the large number of fragments generated. However, visualisation and interpretation of these polymorphisms can be facilitated by a Southern blot hybridisation, where fragments separated by electrophoresis are transferred to a nitrocellulose or nylon membrane and hybridised using specific nucleic acid probes $[21,24,28]$.

Hybridisation of fragments generated by REA with nucleic acid probes diminishes the number of bands produced, facilitating interpretation. DNA probes are designed for specific sequences that are found in multiple copies and in different positions of the chromosome. These probes are tagged, usually with radioactive isotopes or with biotin, and bind to specific sequences of the digested DNA. However, differences in the number and size of bands can be used to discriminate the isolates [21,26,28].

Numerous probes have been designed for the analysis of MRSA, the most frequently used sequence being that of ribosomal RNA (rRNA); this particular technique is denominated ribotyping. This technique is based on the analysis of multiple copies of the chromosomal gene that codes for rRNA, present in several positions that are relatively conserved within species. Ribotyping yields good reproducibility and discriminatory power for epidemiological characterizations of MRSA, however it has a lower capacity of differentiating isolates when compared to other techniques [26,29,30]. A fully automated apparatus for ribotyping is now commercially available, the RiboPrinter ${ }^{\mathrm{TM}}$ Microbial Characterization System (Qualicon, Wilmington, DE, USA). Till now, automated ribotyping has been evaluated in only three studies [3133], and despite its practicality, the discriminatory power has been deemed inferior compared to that of other techniques, such as PFGE and RAPD [31,32]. However, Barbarini et al. [31] have pointed out that 
automated ribotyping can be useful as a screening technique when a large number of isolates are evaluated.

Other DNA probes designed for the study of MRSA epidemiology by Southern blotting include various insertion sequences, such as IS431, IS256 and IS1181, mecA gene probes and the transposon Tn554 (mecA:Tn554) [23,30,34-37]. Typing with probes directed at insertion sequences has a few limitations, as not all MRSA isolates possess these insertion sequences. Therefore, some isolates may be non-typeable [26]. In contrast, all MRSA isolates, by definition, possess the mec $\mathrm{A}$ gene, and transposon Tn 554 has been detected in over $90 \%$ of strains. This particular typing technique consists of the digestion of chromosomal DNA with restriction endonuclease $C l a \mathrm{I}$, followed by the separation of the fragments by agarose gel electrophoresis, transfer of the DNA to a nitrocellulose membrane and sequential hybridisation with probes directed at the mecA gene and transposon Tn554. This particular technique presents problems as the typeability, and its discriminatory power is not quite satisfactory [29].

Yet another technique based on a Southern type hybridisation is binary typing, which was recently described and is currently used by only one group of researchers [26,37]. In this technique, several probes were made by the random amplification of Staphylococcus aureus chromosomal DNA, followed by cloning. The probes generated were tested on several MRSA strains for their specificity and were selected for validation. A binary code was given to the isolates, based on hybridisation, or not, with each probe. All MRSAs turned out to be typeable; the results were stable and reproducible. When the authors used a set of 15 probes, they obtained a discriminatory power superior to that of PFGE. The disadvantage of this technique is the great amount of time needed to obtain results [26,37].

Analysis of Chromosomal DNA by Pulsed-Field Gel Electrophoresis (PFGE)

This technique, developed by Schwarz and Cantor [38], is based on the digestion of bacterial DNA with restriction endonucleases that recognise few sites along the chromosome, generating large fragments of DNA $(10-800 \mathrm{~Kb})$ that can not be separated effectively by conventional electrophoresis. In PFGE, the orientation of the electric field across the gel is periodically changed (pulsed), allowing DNA fragments on the order of megabase pairs to be effectively separated according to size [21,24,26,39-41]. Consequently, PFGE allows for the comparison of chromosomal DNA with much simpler profiles than those generated by high-frequency restriction endonucleases [26]. All bacteria can theoretically by typed by PFGE, and the results are highly reproducible [21].

PFGE requires intact DNA and special care must be taken during the isolation of DNA. In order to avoid the risk of mechanical breakage to DNA molecules during the extraction procedure, each sample is incorporated into low melting point agarose, thus protecting the DNA, and at the same time allowing the free flow of solutions necessary for cell wall lysis and enzymatic digestion of cell proteins. The isolated DNA is then submitted to digestion with restriction endonucleases that recognise few sites along the chromosome. The agarose plugs containing the digested DNA are then submitted to PFGE [21,24,26,39-41].

The DNA fragments migrate towards the anode, however before they begin migrating the fragments have to align themselves with the direction of the electric current. As the time taken for this alignment to occur is dependant on molecular mass, a sharper resolution of fragments is obtained when the direction of the electric current is alternated during electrophoresis. Through this process, larger fragments need a longer time for reorientation to the new electric field, while smaller fragments quickly reorient themselves and start migrating faster. This leaves the larger fragments closer to the origin. The intensity, the angle of the electric current and the frequency with which the electric current alternates the length of time and temperature of electrophoresis can be programmed [42]. Various techniques involving a pulsed field are used for DNA fragment separation, but the most common ones are FIGE (field-inversion gel electrophoresis) and techniques involving the alternation of the angle of the 
electric field, such as the CHEF (contour-clamped homogenous electric field). FIGE is a simpler and less expensive technique, and seems to be best for separating fragments ranging from 0.1 to $200 \mathrm{~Kb}$. In this system, the electric field is simply alternated between forward and reverse directions, the forward pulse lasting three times as long as the reverse pulse. $\mathrm{CHEF}$ is best for the separation of fragments of up to $3 \mathrm{Mb}$ in size, and consists of a hexagonal arrangement of electrodes, used for generating uniform electric fields at angles of $120^{\circ}$. In this way, the fragments move in a straight line, with little or no distortion [42].

PFGE has been used for the investigation of MRSA and has been compared with other methods in several studies [22,29,30,43-47]. Even though a number of restriction endonucleases have been tested, none has shown better performance than SmaI [48-50]. All isolates are typeable and standard strains are reproducible, even after extensive subculturing $[29,43,51,52]$. The discriminatory power is equal to or superior to phenotypic techniques as well as to genotypic techniques such as ribotyping, RAPD, PCRRFLP and inter-IS256 PCR [22,29,45,53]. The results are more reliable than those yielded by REA, due to the fact that there is nointerference from plasmid DNA, as the fragments generated by its digestion are far too small to affect the profile [17]. Due to the aforementioned facts, PFGE has many of the characteristics attributed to an ideal typing technique and has been proposed as the gold standard for MRSA typing [43]. However, there are limitations for the use of PFGE, such as the long time interval until the the final results are obtained and the high cost of reagents and specialised equipment used for this technique [26].

Even though the total number of bands generated is relatively small, there are problems in the interpretation of results, especially in inter-laboratory studies, as small differences in electrophoresis conditions can alter the distance travelled by each band, complicating the comparison between isolates submitted to electrophoresis in different gels [54,55]. However, these limitations do not prevent PFGE from being considered an extremely useful technique used in the characterization of outbreaks [26].
This technique has been extensively used for the comprehension of the epidemiology of both endemic and epidemic MRSA strains. In these situations, the interpretation of the profiles yielded by PFGE is aided by published directives. Tenover et al. [56] proposed a standardised interpretation scheme in order to determine the genetic relationship between strains.

Using this scheme, isolates that possess the same PFGE profile are considered as being identical. Isolates that differ by a single genetic event, reflected by a difference in one to three bands, are considered as being probably related. Isolates that differ in four to six bands (representing two independent genetic events) are considered as being possibly related, and isolates possessing a difference in more than six bands are considered as being unrelated. It is important to highlight that such criteria are applicable only to the analysis of a small number of isolates obtained during epidemiological studies of outbreaks in hospitals or communities during a relatively short period of time (1 to 3 months) [56], where presumably, the genetic variability is limited [41]. These criteria are not applicable for the study of large collections of microorganisms collected during periods of over one year [56].

In Brazil, this technique has been of great importance for the elucidation of the epidemiology of staphylococcal infection, especially that caused by MRSA, which has acquired an endemic character during the last decades. Sader et al. [57], after analysing 30 samples of MRSA isolated from nine hospitals in the city of São Paulo, observed the predominance of an endemic clone, found in eight of the nine hospitals enrolled in the study. In a multi-centre study by Teixeira et al. [18], in which 85 MRSA strains isolated from six hospitals were analysed, $77 \%$ were found to belong to a common electrophoretic profile, designated "A", disseminated throughout all the hospitals enrolled in the study. Similar data was obtained in a study by Oliveira [11], involving MRSA strains isolated from five different regions in Brazil.

Due to the great similarity of MRSA strains throughout Brazil, finding a technique with adequate discriminatory power is a concern. For this reason, even 
when PFGE is used, it is important to take into account epidemiological data when evaluating putative outbreaks, or else a false outbreak may be announced.

Techniques Involving Polymerase Chain Reaction $\underline{(\mathrm{PCR})}$

There are three main stages in polymerase chain reaction. The first, denaturing, takes place at high temperatures, and is necessary for the separation of the double strand into two single strands. In the second stage, there is annealing of the primers present in the reaction mixture to their complementary region in the template DNA. The annealing temperature used is very important as it determines the specificity (stringency) of the reaction. The third stage, synthesis, is polymerisation by means of a thermostable DNA polymerase (Taq DNA polymerase), extending the primers. Taq DNA polymerase works in the presence of $\mathrm{Mg}^{2+}$ ions and the four deoxyribonucleotide triphosphates (dNTPs), and results in the duplication of the region of interest ad libitum. Each complete cycle takes around five minutes and doubles the quantity of DNA produced in the preceding cycles. For an efficient amplification of DNA, 20 to 40 cycles are necessary. In this way, target DNA is amplified approximately a billion fold [40].

PCR gave rise to a variety of techniques with many applications, amongst these, the discrimination between bacterial isolates. Typing techniques involving PCR can be divided into four main groups: PCR-RFLP, PCRribotyping, AP-PCR/RAPD and Rep-PCR [20]. PCR-RFLP [58-63] and PCR-ribotyping [64] are no longer frequently used for MRSA typing, so we shall focus on the other PCR techniques.

The arbitrarily primed PCR (AP-PCR) technique, or RAPD (Random Amplified Polymorphic DNA) is a variation of classic PCR and was proposed by Williams et al. [65] and by Welsh and McCleland [66] for the genetic analysis of microorganisms. This technique involves the random amplification of segments of target DNA using a small primer (of 10 bases) with an arbitrary sequence of nucleotides, that is, one that has no known homology with a target sequence. During
PCR, this primer leads to the amplification of one or more sequences of DNA, generating a set of fragments that work as genetic markers. This technique does not require the digestion of the amplified fragments (called amplicons), because various fragments of different sizes are generated during PCR [40]. The number and size of these fragments are the basis for the typing of an isolate.

The RAPD technique produces genetic identities for all MRSAs and the results have good intralaboratory reproducibility. The advantage of this technique over others is its relative simplicity and quickness. The discriminatory power is variable and depends on the number and nucleotide sequence of the primers used. When a single primer is used, discriminatory power is low, however using three or more primers considerably increases the amount of time spent carrying out this technique, and yet the discriminatory power will still remain poorer than that of PFGE $[67,68]$. Even so, in the investigation of outbreaks, RAPD has permitted the grouping of epidemiologically related isolates and the exclusion of unrelated isolates [47].

In the Repetitive Palindromic Extragenic Elements PCR (Rep-PCR) technique, primers based on short sequences of repetitive elements, which are dispersed throughout the prokaryote kingdom, are used. These elements seem to be conserved within several bacterial genera and species. In this way, molecular profiles are obtained, and the differences between band sizes represent polymorphism in the distances between repetitive elements of different genomes. This technique has been employed for the discrimination of isolates of numerous bacterial species, including Staphylococcus aureus $[39,40,69]$.

Rep-PCR was described by Versalovic et al. [70] for the analysis of the bacterial genome by means of observation of specific standard profiles for strains obtained by PCR amplification of repetitive DNA elements present within the bacterial genome. The repetitive palindromic extragenic elements (Rep) are sequences of 38 base pairs consisting of six degenerated positions and variable loops of five base pairs between each conserved side [71]. This technique 
is easy to use and can be applied to large or small numbers of isolates; it has a higher discriminatory power than many other typing techniques. Numerous studies have demonstrated that the results obtained by RepPCR have a good correlation with those obtained by PFGE, even though the discriminatory power is lower. Several studies employing the Rep-PCR strategy have been described in the literature. The target sequences used for MRSA typing include RepMP3, interIS256 and $\operatorname{Tn} 916$ [10,41,53,72-74].

Del Vecchio et al. [72] used primer RW3A, derived from the RepMP3 sequence of Mycoplasma pneumoniae, to characterize $170 \mathrm{MRSA}$ strains. The PCR products that were generated had highly reproducible and stable patterns, even after extensive subculturing. The discriminatory power was considered as being good. In this same study Rep-PCR was also adapted into an automated format, in which primers marked with fluorescein were used to obtain the Rep profile. The amplified sequences were submitted to polyacrylamide gel electrophoresis, and the bands were then detected by a laser scanner. This technique allowed for the formation of consistent standard profiles, which can be kept as digital images in data banks.

In a study carried out by Van der Zee et al. [10] results obtained by Rep-PCR were compared to that of other genotypic techniques that had already been used for the characterization of the strains. The analysis of results demonstrated that Rep-PCR is as discriminatory as RAPD and PFGE. In comparison to RAPD, Rep-PCR requires an extra step in DNA purification. Therefore, in terms of ease of execution, the utility of the RAPD technique is slightly superior. However, whereas the reproducibility of the Rep-PCR technique was excellent, that of RAPD was low. When Rep-PCR is compared to PFGE, the main advantage of the latter method is the greater ease and rapidity of its execution. Reproducibility was comparable to that of PFGE.

In a multi-centre study carried out by Deplano et al. [74], it was found that the use of region interIS256 presented superior discriminatory power and reproducibility than when the RepMP3 sequence was used. These results disagree with those obtained by
Van der Zee et al. [10]. Deplano et al. [74] suggest that there may be a relationship between geographic origin and polymorphism of the repetitive elements in MRSA strains. Thus, depending on the geographic region one of the two techniques would be the most adequate. Overall, the various authors agree that the employment of Rep-PCR, using either the interIS256 or RepMP3 regions as a sequence target, can be very useful in screening for nosocomial outbreaks of MRSA.

Due to the high prevalence of an MRSA clone in Brazilian hospital environments [11,18], there is the need for the employment of increasingly faster screening techniques, with high discriminatory powers and low costs, that aid in the recognition of outbreaks and that can be used for the characterization of MRSA in hospital laboratories. Taking into account all the data presented in the literature, Rep-PCR seems to be a promising technique, in view of its adequate discriminatory power, good reproducibility and low cost.

\section{Multilocus Sequence Typing (MLST)}

Multilocus Sequence Typing (MLST) is a technique that was derived from Multilocus Enzyme Electrophoresis (MLEE), a phenotypic typing technique involving the electrophoresis of proteins that can be selectively stained.

In MLEE, proteins extracted from the organism that is to be studied are separated by electrophoresis and are subsequently selectively stained. The position of each band generated would reflect the expression of that protein's genotype according to the mobility of the protein. Two bands of the same protein (locus) in different positions would reflect two different proteins with different conformations, and thus, two alleles of the same gene. The allelic profile of a sample confers its type.

There is, however, an obvious drawback: the base sequence (genotype) of a particular locus cannot be directly inferred based on the analysis of the expression of that locus (ultimately, a protein). This is because two different base sequences could express the same protein, or even two proteins with the same electrophoretic mobility, which would be detected as the same band in MLEE. 
To resolve this problem, MLST was developed by Maiden et al. (1998). In MLST, instead of analysing the expression of genes, the genes themselves are analysed by nucleotide sequencing. Different sequences are considered as being distinct alleles of that gene, and are arbitrarily awarded a number for the purpose of identification. As in MLEE, the allelic profile gives the isolate its type [75,76].

Differences found between sequences are not weighted, that is, a point mutation would confer a new allele, as would a recombinational replacement, resulting in the change of many bases. The extent to which the alleles are different is irrelevant, and so is not considered [77].

A number of loci are chosen for each species, usually the internal fragment of housekeeping genes, yielding sequences of approximately 500bp for each locus. Housekeeping genes are chosen due to the fact that they are always necessarily present in a given species, and still present sufficient variation within the species to ensure numerous alleles of that locus [77].

For Staphylococcus aureus, seven loci representing the internal fragments of housekeeping genes were chosen. Each locus is amplified by PCR using primers that anneal to the highly conserved region of the genes, which flank the variable region in between them. The PCR product is sequenced and based upon the sequence obtained, a number representing a previously described allele (or a new one) is attributed to the locus. Approximately 30 alleles per locus have been described for Staphylococcus aureus. Taking into account that seven loci are analysed, there is the possibility of $30^{7}$, over 20 billion different allelic profiles, and therefore different strain types [76].

The seven loci used for Staphylococcus aureus are internal fragments of the following genes: Carbamate kinase $(\operatorname{arc} C)$, Shikimate dehydrogenase (aroE), Glycerol kinase $(g l p F)$, Guanylate kinase $(g m k)$, Phosphate acetyltransferase ( $p t a)$, Triosephosphate isomerase (tpi) and Acetyl coenzyme A acetyltransferase (yqiL).

The MLST technique used for Staphylococcus aureus has been validated by Enright et al. [76] using PFGE. They observed that strain types that were grouped by MLST had similar PFGE profiles, whereas distinct MLST strain types had very different PFGE profiles. The sheer possibility of over $20 \times 10^{9}$ allelic profiles assures MLST discriminatory power.

There is a second advantage to MLST. Because a strain type, defined by its allelic profile, consists of no more than a string of seven numbers, this information is unambiguous and easily transmittable over electronic media around the World. Moreover, databases containing the allelic profiles of countless strain types can be readily consulted over the Internet, unifying and standardising global epidemiology data. In fact, such a database already exists and is accessible at the URL http://www.mlst.net. This site also provides on-line software for sequence analysis.

The drawback of MLST is, of course, its high cost, and the need for the equipment necessary to execute it. This restricts MLST to large centres involved in global epidemiology studies, making it an unlikely contender for a technique used to elucidate a putative outbreak in a hospital.

MLST is a very recent technique that is gaining popularity among researchers enticed by its reproducibility and standardisation, allied to its more than satisfactory discriminatory power and ease of interpretation. However, due to its wider acceptance, PFGE still remains the gold standard for MRSA typing.

\section{Conclusions}

Even though standardised criteria for the interpretation of the Rep-PCR technique have not yet been indicated, it presents good discriminatory power and excellent intra-laboratory reproducibility. Rep-PCR is a practical, easily executed technique, that can be used for screening, especially in laboratories that lack more specialised equipment, such as those used for PFGE, or DNA sequencers.

Pulsed Field Gel Electrophoresis still remains the gold standard for MRSA typing, in spite of it being a lengthy and elaborate technique. Ways to effectively enhance its reproducibility, especially its inter-laboratory reproducibility, would further validate it as the technique of choice. Nevertheless, perhaps due to its relatively 
medium to low cost and to the fact that it has been around for quite some time already, PFGE is ultimately the most used and recommended technique for resolving the typing drawbacks of other, simpler techniques.

Because MRSA clones have low genetic variability, a constant burden is finding a technique with sufficient discriminatory power to differentiate the strains into epidemiologically related and non-related groups. One way around this problem is to use more than one technique in a study. This would ensure greater discrimination between strains, as the deficiencies of one technique would be covered by the advantages of the other.

Molecular typing techniques are invaluable tools for the assessment of putative MRSA outbreaks and so should be extensively used for this purpose.

\section{Acknowledgements}

We are indebted to Dr. Silvia Figueiredo Costa for her invaluable suggestions concerning this manuscript. Financial support was provided by CAPES.

\section{References}

1. Kluitmans J., van Belkum A., Verbrugh H. Nasal carriage of Staphylococcus aureus: epidemiology, underlying mechanisms and associated risks. Clin Microbiol Rev 1997;10:505-20.

2. Rubin R.J., Harrington C.A., Poon A., et al. The economic impact of Staphylococcus aureus infection in New York city hospitals. Emerging Infect Dis Atlanta 1999;5: 9-17.

3. Lowy F.D. Staphylococcus aureus infections. N Engl J Med 1998;339:520-32.

4. Bukharie H.A., Abdelhadi M.S., Saeed I.A., et al. Emergence of methicillin-resistant Staphylococcus aureus as a community pathogen. Diagn Microbiol Infect Dis 2001;40:1-4.

5. Chambers H.F. The changing epidemilogy of Staphylococcus aureus Emerging Infect Dis 2001; 7:178-82.

6. Jevons M.P. 'Celbenin'-resistant staphylococci. Br Med J 1961; 1:124-5.

7. Hiramatsu K., Ito T., Hanaki H. Mechanisms of methicillin and vancomycin in Staphylococcus aureus. Ballière's Clin Infect Dis 1999;5:221-42.

8. Fluckiger U., Widmer A.F. Epidemiology of methicillinresistant Staphylococcus aureus. Chemotherapy 1999;45:121-34.
9. Fluit A.C., Wielders C.L.C., Verhoef J., Schimtz F.J. Epidemiology and susceptibility of 3.051 Staphylococcus aureus isolates from 25 university hospitals participating in the European SENTRY study. J Clin Microbiol 2001;39:3727-32.

10. van der Zee A., Verbakel H., van Zon J.C., et al. Molecular genotyping of Staphylococcus aureus strains: comparison of repetitive element sequence-based PCR with various typing methods and isolation of a novel epidemicity marker. J Clin Microbiol 1999;37:342-9.

11. Oliveira G.A. Caracterização de cepas de Staphylococcus aureus isoladas de diferentes regiões do Brasil baseada em métodos fenotípicos e genotípicos. São Paulo, 1998. 164p. (Dissertação de Mestrado - Faculdade de Ciências Farmacêuticas - USP).

12. Wey S.B., Cardo D.M., Halker E., et al. Distribution and analysis of 8.268 nosocomial infections at the Hospital São Paulo: 1985-1989. Rev Hosp São Paulo 1990; 1:169-74.

13. Sader H.S., Pignatari A.C., Hollis, et al. Oxacillin and quinolone-resistant Staphylococcus aureus in São Paulo, Brazil: a multicenter molecular epidemiology study. Infect Control Hosp Epidemiol 1993;14:260-4.

14. Caiaffa Filho H.H., Lima M.P., Sinto S.I., et al. Avaliação da sensibilidade a teicoplanina e vancomicina, em Staphylococcus aureus e Staphylococcus coagulase negativa. Rev Assoc Med Bras 1994;40:77-84.

15. Schmitz F.J., Steiert M., Tichy H.V., et al. Typing of methicillin-resistant Staphylococcus aureus isolates from Düsseldorf by six genotypic methods. J Med Microbiol 1998; 47:341-51.

16. Kreiswirth B., Kornblum J., Arbeit R., et al. Evidence for a clonal origin of methicillin resistance in Staphylococcus aureus. Science 1993;259:227-30.

17. Struelens M.J., Deplano A., Godard C., et al. Epidemiologic typing and delineation of genetic relatedness of methicillin-resistant Staphylococcus aureus by macrorestriction analysis of genomic DNA by using pulsed-field gel electrophoresis. J Clin Microbiol 1992; 30:2599-605.

18. Teixeira L.A., Resende C.A., Ormonde L.R., et al. Geographic spread of epidemic multiresistant Staphylococcus aureus clone in Brazil. J Clin Microbiol 1995;33:2400-04.

19. van Leeuwen W., van Belkum A., Kreiswirth B., Verbrugh H. Genetic diversification of methicillin-resistant Staphylococcus aureus as a function of prolonged dissemination and as measured by binary typing and other genotyping methods. Res Microbiol 1998; 149:497-507.

20. Power E.G.M. RAPD-typing in microbiology: a technical review. J Hosp Infect 1996;34:247-65. 
21. Arbeit R.D. Laboratory procedures for the epidemiologic analysis of microorganisms. In: Murray P.M., Baron E.J., Pfaller M.A., Tenover F.C., Yolken R.H., eds. Manual of clinical microbiology. Washington: ASM Press, 1999.

22. Struelens M.J., European study group on epidemiological markers. Consensus guidelines for appropiate use and evaluation of microbial epidemiologic systems. Clin Microbiol Infect 1996; 2:2-11.

23. Struelens M.J. Molecular epidemiologic typing systems of bacterial pathogens: current issues and perspectives. Mem Inst Oswaldo Cruz 1998;93:581-5.

24. Maslow J.N., Mulligan M.E., Arbeit R.D. Molecular epidemiology: application of contemporary techniques to the typing of microorganisms. Clin Infect Dis 1993; 17:153-64.

25. Hartstein A.I., Phelps C.L., Kwok R.Y.Y., Mulligan M.E. In vivo stability and discriminatory power of methicillinresistant Staphylococcus aureus typing by restriction endonuclease analysis of plasmid DNA compared with those of other molecular methods. J Clin Microbiol 1995;33:2022-6.

26. Weller T.M.A. Methicillin-resistant Staphylococcus aureus typing methods: wich should be the international standard? J Hosp Infect 2000;44:160-72.

27. Jordens J.Z., Hall L.M.C. Characterisation of methicillinresistant Staphylococcus aureus isolates by restriction endonuclease digestion of chromosomal DNA. J Med Microbiol 1988;27:117-23.

28. Busch U., Nitschko H. Methods for the differentiation of microorganisms. J Chromatogr B: Biomed Sci Appl 1999;722:263-78.

29. Tenover F., Arbeit R., Archer G. Comparison of traditional and molecular methods of typing isolates of Staphylococcus aureus. J Clin Microbiol 1994;32:407-15.

30. Yoshida T., Kondo N., Hanifah Y.A., Hiramatsu K. Combined use of ribotyping, PFGE and IS431 typing in the discrimination of nosocomial strains of methicillinresistant Staphylococcus aureus. Microbiol Immunol 1997;41:687-95.

31. Barbarini D., Fumagalli P., Marone P., et al. Methicillinresistant Staphylococcus aureus (MRSA) in an intensive care unit: a one year survey. Infez Med 2001;9:237-45.

32. Fung C.P., Ho M.W., Wang F.D., et al. Investigation of an outbreak caused by methicillin-resistant Staphylococcus aureus in a cardiovascular surgery unit by ribotyping, randomly amplified polymorphic DNA and pulsed-field gel electrophoresis. APMIS 2001;109:474-80.

33. Iinuma Y. Identification and epidemiologic investigation of bacteria by the Riboprinter Microbial Characterization System, the automated ribotyping system. Rinsho Byori 2001;49:1129-32.
34. Morvan A., Aubert S., Godard C., El Solh N. Contribution of a typing method based on IS256 probing of SmaI-digested cellular DNA to discrimination of European phage type 77 methicillinresistant Staphylococcus aureus strains. J Clin Microbiol 1997;35:1415-23.

35. Symms C., Cookson B., Stanley J., Hookey J.V. Analysis of methicillin-resistant Staphylococcus aureus by IS 1181 profiling. Epidemiol Infect 1998; $120: 271-9$.

36. Wei M., Udo E.E., Grubb W.B. Typing of methicillinresistant Staphylococcus aureus with IS256. FEMS Microbiol Lett 1992; 99:175-80.

37. van Leeuwen W., Verbrugh H., van der Velden J., et al. Validation of binary typing for Staphylococcus aureus strains. J Clin Microbiol 1999;37:664-74.

38. Schwartz D.C., Cantor C.R. Separation of yeast chromosome-sized DNAs by pulsed field gradient gel electrophoresis. Cell 1984;37:67-75.

39. Swaminathan B., Matar G.M. Molecular typing methods. In: Persing D.H., Smith T.F., Tenover F.C., White T.J., eds. Diagnostic molecular microbiology: principles and applications. Washington: ASM 1993:26-50.

40. Farber J.M. An introduction to the hows and whys of molecular typing. J Food Prot 1996;59:1091-101.

41. Olive D.M., Bean P. Principles and applications of methods for DNA-based typing of microbial organisms. J Clin Microbiol 1999;37:1661-9.

42. Birren B.W., Lai E. Pulsed field gel electrophoresis: a practical guide. San Diego: Academic Press, 1993.

43. Bannerman T.L., Hancock G.A., Tenover F.C., Miller J.M. Pulsed-field gel electrophoresis as a replacement for bacteriophage typing of Staphylococcus aureus. J Clin Microbiol 1995;33:551-5.

44. Chiou C., Wei H., Yang L. Comparison of pulsed-field gel electrophoresis and coagulase gene restriction profile analysis techniques in the molecular typing of Staphylococcus aureus. J Clin Microbiol 2000;38:2186-90.

45. Kumari D.N.P., Keer V., Hawkey P.M., et al. Comparison and application of ribosome spacer DNA amplicon polymorphisms and pulsed-field gel electrophoresis for differentiation of methicillin-resistant Staphylococcus aureus strains. J Clin Microbiol 1997;35:881-5.

46. Oliveira G.A., Levy C.E., Mamizuka E.M. Staphylococcus aureus apresentando resistência intermediária a vancomicina: mecanismos de resistência, detecção laboratorial e perspectivas de emergência no Brasil. J Bras Patol 2000;36:96-102.

47. van Belkum A., Kluitmans J., van Leeuwen, W., et al. Multicenter evaluation of arbitrarily primed PCR for typing of Staphylococcus aureus strains. J Clin Microbiol 1995;33:1537-47. 
48. Carles-Nurit M.J., Christophle B., Broche S., et al. DNA polymorphisms in methicillin-susceptible and methicillin-resistant strains of Staphylococcus aureus. J Clin Microbiol 1992;30:2092-6.

49. Ichiyama S., Ohta M., Shimokata K., et al. Genomic DNA fingerprinting by pulsed-field electrophoresis as an epidemiological marker for study of nosocomial infections caused by methicillin-resistant Staphylococcus aureus. J Clin Microbiol 1992;30:2092-6.

50. Prevost G., Jaulhac B., Piemont Y. DNA fingerprinting by pulsed-field gel electrophoresis is more effective than ribotyping in distinguishing among methicillin-resistant Staphylococcus aureus isolates. J Clin Microbiol 1992;30:967-73.

51. Blanc D.S., Struelens M.J., Deplano A., et al. Epidemiological validation of pulsed-field gel electrophoresis patterns for methicillin-resistant Staphylococcus aureus. J Clin Microbiol 2001;39:3442-5.

52. Tenover F.C., Arbeit R.D., Goering R.V. How to select and interpret molecular strain typing methods for epidemiological studies of bacterial infections: a review for healthcare epidemiologists. Infect Control Hosp Epidemiol 1997; 18:426-38.

53. Deplano A., Vaneechoutte M., Verschraegen G., Struelens M.J. Typing of Staphylococcus aureus and staphylococcus epidermidis strains by PCR analysis of inter-IS256 spacer length polymorphisms. J Clin Microbiol 1997;35:2580-7.

54. Cookson B.D., Aparicio P., Deplano A., et al. Inter-centre comparison of pulsed-field gel electrophoresis for the typing of methicillin-resistant Staphylococcus aureus. J Med Microbiol 1996;44:179-84.

55. van Belkum A., van Leeuwen W., Kaufmann M.E., et al. Assessment of resolution and intercenter reproducibility of results of genotyping Staphylococcus aureus by pulsedfield electrophoresis of SmaI macrorestriction fragments: a multicenter study. J Clin Microbiol 1998;36:1653-9.

56. Tenover F., Arbeit R., Goering R., et al. Interpreting chromosomal DNA restriction patterns produced by pulsed-field gel electrophoresis: criteria for bacterial strain typing. J Clin Microbiol 1995;33:2233-9.

57. Sader H.S., Pignatari A.C., Hollis R.J., Jones R.N. Evaluation of interhospital spread of methicillin-resistant Staphylococcus aureus in São Paulo, Brazil, using pulsed-field gel electrophoresis of chromosomal DNA. Infect Control Hosp Epidemiol 1994;15:320-3.

58. Goh S., Byrne S., Zhang J.L., Chow A.W. Molecular typing of Staphylococcus aureus on the basis of coagulase gene polymorphisms. J Clin Microbiol 1992;30:1642-5.

59. Schwarzkopf A., Karch H. Genetic variation in Staphylococcus aureus coagulase genes: potential and limits for use as epidemiological marker. J Clin Microbiol 1994;32:2407-12.
60. Kobayashi N., Taniguchi K., Kojima K. Analysis of methicillin-resistant and methicillin-susceptible Staphylococcus aureus by a molecular typing method based on coagulase gene polymorphisms. Epidemiol Infect 1995;115:419-26.

61. Hookey J.V., Richardson J.F., Cookson B.D. Molecular typing of Staphylococcus aureus based on restriction fragment length polymorphisms and DNA sequence analysis of the coagulase gene. J Clin Microbiol 1998;36:1083-9.

62. Frenay H.M., Theelen J.P., Schouls L.M., et al. Discrimination of epidemic and nonepidemic methicillinresistant Staphylococcus aureus strains on the basis of protein A gene polymorphism. J Clin Microbiol 1994;32:846-7.

63. Hoefnagels-Schuermans A., Peetermans W.E., Struelens M.J., et al. Clonal analysis and identification of epidemic strains of methicillin-resistant Staphylococcus aureus by antibiotyping and determination of protein $\mathrm{A}$ and coagulase gene polymorphisms. J Clin Microbiol 1997;35:2514-20.

64. Gürtler V., Barrie H.D. Typing of Staphylococcus aureus strains by PCR-amplification of variable-length $16 \mathrm{~S}-23 \mathrm{~S}$ rDNA spacer regions: characterization of spacer sequences. Microbiology 1995;141:1255-65.

65. Williams J.G., Kubelik A.R., Livak K.J., et al. DNA polymorphisms amplified by arbitrary primers are useful genetic markers. Nucleic Acids Res 1990;18:6531-5.

66. Welsh J., McCleland M. Fingerprinting genomes using PCR with arbitrary primers. Nucleic Acids Res 1990;18:7213-8.

67. Saulnier P., Bourneix C., Prevost G., Andremont A. Random amplified polymorphic DNA assay is less discriminatory than pulsed-field gel electrophoresis for typing strains of methicillin-resistant Staphylococcus aureus. J Clin Microbiol 1993;31:982-5.

68. Struelens M.J., Bax R., Deplano A., et al. Concordant clonal delineation of methicillin-resistant Staphylococcus aureus by macrorestriction analysis and polymerase chain reaction genome fingerprinting. J Clin Microbiol 1993;31:1064-70.

69. Jeršek B., Tcherneva E., Rijpens N., Herman L. Repetitive element sequence-based PCR for species and strain discrimination in the genus Listeria. Lett Appl Microbiol 1996;23:55-60.

70. Versalovic J., Kapur V., Lupski J.R. Distribuition of repetitive DNA sequences in eubacteria and application to fingerprinting of bacterial genomes. Nucleic Acids Res 1991;19:6823-31.

71. Stern M.J., Ames G.F.L., Smith N.H., et al. Repetitive extragenic palindromic sequences: a major component of the bacterial genome. Cell 1984;37:1015-26. 
72. Del Vecchio V.G., Petroziello J.M.M., Gress M.J., et al. Molecular genotyping of methicillin-resistant Staphylococcus aureus via fluorophore-enhanced repetitive-sequence PCR. J Clin Microbiol 1995;33:2141-4.

73. Cuny C., Witte W. Typing of Staphylococcus aureus by PCR for DNA sequences flanked by transposon Tn916 target region and ribosomal binding site. J Clin Microbiol 1996; 34: 1502-5.

74. Deplano A., Schuermans A., van Eldere J., et al. Multicenter evaluation of epidemiological typing of methicillinresistant Staphylococcus aureus strains by repetitive-element PCR analysis. J Clin Microbiol 2000;38:3527-33.

75. Maiden M.C., Bygraves J.A., Feil E., et al. Multilocus sequence typing: a portable approach to the identification of clones within populations of pathogenic microorganisms. Proc Natl Acad Sci USA 1998;95:3140-5.

76. Enright M.C., Day N.P., Davies C.E., et al. Multilocus sequence typing for characterization of methicillinresistant and methicillin-susceptible clones of Staphylococcus aureus. J Clin Microbiol 2000;38:1008-15.

77. Imperial College of Science, Technology and Medicine. Further information. Available at: <http://fi-srvmlst1ide.sm.med.ic.ac.uk/new/misc/further info.htm $>$. Accessed on: May 13th, 2002. 